Artikel IImiah

\title{
PENGARUH KEMUDAHAN, MANFAAT DAN PERSEPSI RISIKO TERHADAP KEPUASAN BELANJA ONLINE DALAM MENGGUNAKAN E-COMMERCE SHOPEE DI KELURAHAN TANJUNGSARI, KECAMATAN TAMAN SIDOARJO
}

\author{
Nurul Haqiqi ${ }^{1}$, Untung Lasiyono², Tri Ari Prabowo ${ }^{3}$ \\ Universitas PGRI Adi Buana \\ Surabaya \\ Email : Haqiqi565@gmail.com
}

\begin{abstract}
ABSTRAK
Maksud dari penelitian ini untuk menganalisis dan membuktikan pengaruh variabel Kemudahan, variabel Manfaat, dan variabel persepsi risiko terhadap Kepuasan belanja online dalam menggunakan e-commerce Shopee di Kelurahan Tanjungsari, Kecamatan Taman Sidoarjo. Jenis penelitian ini menggunakan metode kuantitatif. Populasi yang diteliti yaitu warga Kelurahan Tanjungsari, Kecamatan Taman Sidoarjo yang pernah melakukan belanja online dalam menggunakan e-commerce Shopee dengan kategori karakterisitik responden yang sudah ditentukan. Sampel ini diambil dengan menggunakan metode accidential sampling serta sampel sebesar 108 responden. Peneliti mengumpulkan data menggunakan kuesioner yang telah diuji berdasarkan perhitungan SPSS. Peneliti menganalisa data dengan teknik analisis regresi liner berganda. Berdasarkan penelitian yang telah diuji dan dianalisa dapat disimpulkan bahwa dari ketiga variabel Kemudahan, Manfaat dan Persepsi risiko secara keseluruhan memperoleh hasil positif dan signifikan terhadap kepuasan belanja online dalam menggunakan e-commerce Shopee, diketahui dari hasil uji $F$ dengan signi $0.000<0.05$ maka variabel Kemudahan, Manfaat dan Persepsi risiko secara individu memperoleh hasil positif dan signifikan terhadap kepuasan belanja online dalam menggunakan e-commerce Shopee.
\end{abstract}

Kata Kunci : Belanja Online, Kemudahan, Manfaat, Persepsi Risiko, Kepuasan Belanja Online

\section{ABSTRACT}

The purpose of this study is to analyze and prove the effect of the Ease variable, Benefit variable, and risk perception variable on online shopping satisfaction in using Shopee e-commerce in Tanjungsari Village, Taman Sidoarjo District. This type of research uses quantitative methods. The population studied is the residents of Tanjungsari Subdistrict, Taman Sidoarjo District who have done online shopping using Shopee e-commerce with the specified characteristics of the respondents. 
This sample was taken using the accidential sampling method and a sample of 108 respondents. Researchers collected data using a questionnaire that was tested based on SPSS calculations. The researcher analyzed the data with multiple linear regression analysis techniques. Based on research that has been tested and analyzed, it can be concluded that from the three variables of Ease, Benefits and Risk Perception as a whole get positive and significant results on the satisfaction of online shopping using Shopee e-commerce, it is known from the results of the $F$ test with signi $0.000<0.05$ then the Ease variable, Benefits and individual risk perceptions get positive and significant results on online shopping satisfaction using Shopee e-commerce.

Keywords: Online Shopping, Convenience, Benefits, Risk Perception, Online Shopping Satisfaction

\section{PENDAHULUAN}

Di Era global saat ini, perkembangan teknologi di dunia khususnya Indonesia telah berhasil mencapai kemajuan yang sangat luar biasa. Hadirnya teknologi internet yang bertambah canggih dan modern memungkinkan pengguna internet dapat memperoleh manfaat komunikasi yang semakin luas tanpa batasan ruang dan waktu. Ditambah adanya kemudahan dalam mengakses internet dimanapun dan kapanpun memungkinkan pengguna internet dapat dengan mudah membeli kebutuhan mereka melalui e-commerce. Hal ini dapat berdampak pada perubahan tingkah laku konsumen dalam memenuhi kebutuhan dan keinginannya.

Perubahan tingkah laku konsumen sangat mempengaruhi persaingan bisnis yang sedang berjalan. Dimana sebagian besar masyarakat ingin segala sesuatunya menjadi lebih praktis, mudah, dan cepat, maka dari sini terbentuklah peluang usaha bagi pelaku bisnis untuk memasarkan produk melalui ecommerce, yaitu suatu cara untuk memudahkan konsumen dalam makukan belanja online dengan akses internet tanpa batas.

Seperti yang dialami oleh masyarakat di kelurahan Tanjungsari, Kecamatan Taman, Sidoarjo. Saat ini sebagian besar masyarakat di Desa Tanjungsari lebih memilih belanja atau membeli segala kebutuhan melalui ecommerce. Alasannya karena dirasa lebih mudah dan praktis, selain harga yang ditawarkan beragam sehingga menarik minat mereka untuk membeli segala kebutuhannya melalui online shop.

Adanya fenomena ini menimbulkan adanya perubahan pada tingkah laku konsumen dalam membeli ataupun mengkonsumsi suatu produk. sehingga dapat dikatakan bahwa perubahan pada perilaku konsumen memungkinkan seseorang mempunyai keinginan untuk membeli suatu produk, agar barang yang dibeli sama dengan keinginannya sehingga dapat menambah kepercayaan dan kepuasan dalam melakukan belanja online.

Apalagi dengan maraknya belanja melalui media internet, mereka akan lebih konsumtif dalam membeli prduk serta didukung koneksi internet yang 
memudahkan mereka dalam berbelanja online.

Akan tetapi, seringkali masyarakat Tanjungsari mempunyai rasa antisipasi terhadap maraknya online shop. Kurangnya rasa percaya diri membuat mereka enggan bertransaksi di situs belanja online. Mereka mengira bahwa belanja online sebagai jalan bagi beberapa orang untuk melakukan tindak kejahatan seperti penipuan, penyalahgunaan informasi pribadi seseorang, barang yang diterima tidak sesuai deskripsi atau gambar, dan bisa saja barang tersebut tidak dikirim atau diterima.

Dari beberapa risiko di atas dapat mempengaruhi tingkat kepuasan dalam melakukan belanja online. (Elvandri, 2011) mengatakan kepuasan konsumen dalam melakukan transaksi online ini diindikasi berpengaruh terhadap kepercayaan konsumen yang pada akhirnya akan mempengaruhi sikap konsumen dalam melakukan pembelian. Apabila konsumen telah percaya terhadap kualitas suatu barang, kualitas pelayanan yang sangat baik serta pengiriman barang yang aman, maka dikatakan konsumen tersebut merasakan kepuasan belaja di toko tersebut.

Beberapa kerugian yang dialami sebagian masyarakat, maka Pemerintah Republik Indonesia telah mengeluarkan peraturan Undang-Undang yaitu UU no. 11 thn. 2008 mengenai Informasi dan Transaksi Elektronik pasal 9, pasal 10 ayat 1 , pasal 15 , pasal 17 ayat 1 dan 2 dengan jelas memberikan peraturan kepada pelaku usaha agar menyelenggarakan transaksi elektronik secara andal, aman dan bertanggungjawab.

Diantara beberapa online shop yang sedang menjamur saat ini yaitu Shopee. Alasannya karena shopee sering memberikan promo gratis ongkir yang cukup menguntungkan, selain itu adanya promo mulai dari program flash sale, gratis ongkir, cash back, diskon secara besar-besaran pada saat event tertentu. produk yang dijual lebih lengkap dengan harga yang bervariasi mulai dari fashion, hingga kebutuhan sehari-hari. Keuggulan lainya menyediakan banyak pilihan pembayaran mulai dari COD (Cash On Delivery) hingga pembayaran melalui ATM dengan menggunakan Internet Banking.

\begin{tabular}{ccc}
\hline No. & Nama & Ket. \\
\hline 1 & Gambar 1 & $\begin{array}{c}\text { Kerangak } \\
\text { Konseptual } \\
\text { Uji }\end{array}$ \\
2 & Gambar 2 & $\begin{array}{c}\text { heterokedastisitas } \\
\text { Karakteristik } \\
\text { Responden }\end{array}$ \\
3 & Tabel 1 & Uji Validitas \\
4 & Tabel 2 & Uji Reliabilitas \\
5 & Tabel 3 & Uji Normalitas \\
6 & Tabel 4 & Uji Multikolinearitas \\
7 & Tabel 5 & Regresi liner \\
8 & Tabel 6 & berganda \\
& Uji t \\
9 & Tabel 7 & Uji f \\
10 & Tabel 8 &
\end{tabular}

TINJAUAN PUSTAKA DAN HIPOTESIS Landasan Teori

\section{E-Commerce}

E-Commerce menurut Kotler \& Amstrong (2012) adalah saluran online 
yang dapat dijangkau seseorang melalui media komputer yang dilakukan oleh pengusaha dalam menjalankan kegiatan usahanya dan digunakan konsumen untuk mendapatkan informasi yang diinginkan dengan memanfaatkan media komputer dalam hal penyediaan jasa informasi dan komunikasi terhadap pengguna agar dapat menentukan pilihannya.

\section{Kemudahan}

Menurut (Davis, 1998) dalam Amijaya (2010:214) mendefinisikan kemudahan pengguna (ease of use) sebagai suatu tingkatan dimana seorang percaya bahwa dengan menggunakan teknologi, suatu pekerjaan lebih mudah dipahami dan mudah digunakan.

Aplikasi belanja online akan menyediakan petunjuk dan layanan yang dapat memudahkan calon konsumen pada saat bertransaksi online, seperti metode pembayaran, cara mendapatkan produk, pengisian data pribadi, dan fitur lainnya yang dapat dipelajari dengan mudah. Dengan begitu mereka tidak perlu khawatir dan merasa kesulitan dan dapat bertransaksi secara aman dan nyaman.

\section{Manfaat}

Menurut (Wahyuningtyas dan Widiastuti, 2015) manfaat adalah suatu proses dimana seorang individu menganggap bahwa dengan menggunakan suatu teknologi dapat meningkatkan kemampuan dalam bekerja tanpa harus mengorbankan waktu dan tenaga lebih, dengan begitu pekerjaan dapat diselesaikan dalam waktu yang singkat.

Faktor ini menjelaskan aspek dari menghemat waktu seperti pemilihan produk dapat dilakukan dimanapun dan kapanpun tanpa harus keluar rumah, tanpa harus meninggalkan pekerjaan lainnya, selain itu konsumen juga bisa mendapatkan informasi secara detail mengenai toko online shop mulai dari spesifikasi produk, testimoni produk, dan harga produk ketersedian produk.

\section{Persepsi Risiko}

Menurut Sciffman dan Kanuk (2010) mendefinisikan persepsi risiko yaitu suatu ketidakpastian yang di hadapi oleh konsumen ketika mereka tidak dapat meramalkan dampak dan keputusan pembelian yang mereka pilih.

Variabel ini menjelaskan tentang mereka yang merasa khawatir dan dirugikan apabila pada saat melakukan transaksi online terjadi suatu hal yang tidak diharapkan dalam membeli suatu barang misalkan produk yang dibeli dibeli berbeda dengan gambar, barang cacat pada saat pengiriman, dan penyalahgunaan informasi pribadi seseorang.

\section{Belanja Online}

Menurut Mujiana dan Elissa (2013) mengartikan dimana konsumen secara langusung membeli produk, jasa dan lain-lain dari si penjual secara online dan realtime secara langsung tanpa media perantara melalui internet. singkatnya belanja online atau buying 
online merupakan suatu transaksi jual beli barang atau jasa yang dilakukan secara online oleh konsumen dan pengusaha dengan menginstal aplikasi belanja online atau e-commerce melalui media internet yang harus terkoneksi wifi atau kuota data.

Kini konsumen dapat membeli berbagai kebutuhan dengan menggunakan smarthphone atau komputer yang terhubung internet. Melalui aplikasi belanja online yang sedang ramai digunakan. Belanja online sudah menjadi gaya hidup khusunya masyarakat Indonesia yang berdampak pada perubahan tingkah laku konsumen.

\section{Kepuasan Pelanggan}

Kotler (2010:10) mengartikan kepuasan pelanggan sebagai "sejauh mana mereka percaya baha kualitas produk atau jasa dapat memenuhi harapan pembeli.

Dari pernyataan di atas dapat ditarik kesimpulan bahwa konsumen akan memberikan penilaian yang baik terhadap layanan dan performance produk atas kepuasan yang dirasakan dari membeli suatu produk ataupun jasa. Sebaliknya pembeli akan memberikan penilaian yang negatif jika produk yang dibeli tidak sesuai yang diharapkan. Apabila pelangga puas biasanya akan melakukam pembelian ulang barang kepada toko online yang sama dan cenderung tidak ingin membeli produk di tempat lainnya.

\section{Kerangka Konseptual}

Berikut ini merupakan gambar kerangka konseptual dari Kepuasan Belanja Online Dalam Menggunakan ECommerce Shopee Di Kelurahan Tanjungsari, Kecamatan Taman Sidoarjo.

Gambar 1. Kerangka Konseptual

Hipotesis adalah hasil kesimpulan

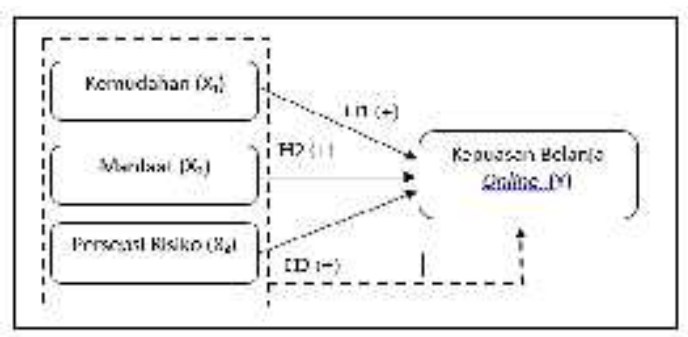

yang tidak pasti atas suatu serangkaian masalah yang sedang diteliti, yang mana rangkaian masalah penelitian digunakan dalam suatu pertanyaan .

Hipotesis dalam penelitian ini adalah :

1. Kemudahan berdampak secara pasti dan relevan kepada kepuasan belanja online

2. Manfaat berdampak secara pasti dan relevan kepada kepuasan belanja online.

3. Persepsi risiko berdampak secara pasti dan relevan kepada kepuasan belanja online.

4. Kemudahan, manfaat dan persepsi risiko berdampak secara pasti dan relevan kepada kepuasan belanja online.

\section{METODE}

Populasi, Sampel, dan Teknik Pengumpulan Data

Populasi yang digunakan dalam penelitian ini yaitu penduduk yang tinggal 
di Kelurahan Tanjungsari Kecamatan Taman, Sidoarjo yang kemudian diambil sampel sebanyak 108 resonden. Sampel diambil berdasarkan prosedur non probability sampling serta tenik accidential sampling. Metode pengumpulan data dilakukan dengan menggunakan sebar kuesioner dan wawancara pada penduduk tanjungsari, dengan meggunakan table skala liket dalam merumuskan setiap butir pertanyaan sehingga dapat dijadikan sebagai tolak ukur.

\section{Teknik Analisa Data}

Penelitian ini menggunakan beberapa uji instrumen yaitu uji validitas dan uji reliabilitas. Uji validitas bertujuan agar pertanyaan-pertanyaan di dalam kuesioner dapat terdeteksi, selanjutnya uji reliabilitas dipakai untuk mendeteksi pertanyaan apabila jawaban pada hasil kuesioner stabil atau konsisten. Untuk mengetahui adanya penyimpangan atau tidak akan dilakukan uji asumsi klasik yang mencakup dari beberapa uji yaitu uji normalitas, multikoliniaritas dan heterokedastisitas.

Uji normalitas digunakan untuk menganalisa apabila variabel terikat dan variabel bebas keduanya bersifat normal atau tidak. Uji multikoliniaritas digunakan untuk mendektesi apakah model regresi ditemukan adanya korelasi antara variabel bebas atau terikat (Ghozali, 2011:105), sedangkan uji heterokedastisitas digunakan untuk mengetahui adanya penyimpangan atau tidak dikarenakann adanya perbedaan varian residual pada saat penelitian dalam metode regresi .

Pengujian hipotesis yang dipakai adalah uji t dan uji f. Uji t bertujuan untuk menganalisis dampak secara sendirisendiri variabel bebas terhadap variabel terikat, sedangkan uji $f$ bertujuan untuk mengetahui dampak bersama variabel bebas kepada variabel terikatnya.

Peneliti menganalis data menggunakan uji coba regresi linear berganda dengan menggunakan rumus dibawah ini :

$$
Y=\alpha+\beta 1 X 1+\beta 2 X 2+\beta 3 X 3+e
$$

Keterangan:

$\mathrm{Y}=$ Kepuasan Belanja

$\alpha=$ nilai konstanta

$\beta 1=$ koefisien regresi kemudahan

$\mathrm{X} 1$ = kemudahan

$\beta 2=$ koefisien regresi manfaat

$\mathrm{X} 2$ = manfaat

B3 = koefisien regresi persepsi risiko

$\mathrm{X} 3$ = persepsi risiko

$\mathrm{e}=$ pengganggu

\section{HASIL DAN PEMBAHASAN}

Hasil dari penelitian ini menunjukan bahwa pada setiap item pernyataan pada kuesioner sesuai dengan varibel yang diteliti, maka dapat ditarik kesimpulan bahwa varibel kemudahan, manfaat dan persepsi risiko, dan kepuasan belanja online dinyatakan valid karena memiliki nilai alpha cronbach sebesar $>0.60$. 
Tabel 1. Karakteristik Responden

\begin{tabular}{|c|c|c|c|c|}
\hline $\begin{array}{c}\text { No } \\
1 \\
\end{array}$ & 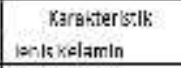 & $\begin{array}{l}\text { Xategon } \\
\text { |acl- }=k \mid\end{array}$ & $\begin{array}{c}\text { Trabuensl } \\
83 \\
\end{array}$ & $\begin{array}{c}\text { Fresentsse } \\
19,1\}\end{array}$ \\
\hline \multirow{6}{*}{3} & \multirow{5}{*}{$|1|<\mid \lambda$} & Deracenata & s5 & $5 n, 7 \%$ \\
\hline & & onl & $\mathrm{T}: \mathrm{K}$ & Bala,ith \\
\hline & & 17-3) Tahun & 34 & $39,2 \%$ \\
\hline & & is 28 isher & 36 & $23,3 \%$ \\
\hline & & cos Intun & 3) & 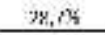 \\
\hline & & $\begin{array}{l}\therefore 3 \text { livian } \\
\text { conl }\end{array}$ & $\begin{array}{ll}2 i \\
z i\end{array}$ & $25.3 \%$ \\
\hline \multirow[t]{5}{*}{2} & Fukn:as' & 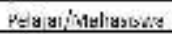 & 24 & $22.2 \%$ \\
\hline & & $10 w 2$ & 22 & $25,6 \%$ \\
\hline & & Ratrementi Finesly & 33 & $36,6 \%$ \\
\hline & & til & 2 & $11,6 \%$ \\
\hline & & Total & $6 n$ & $\operatorname{tnn} \theta$ \\
\hline \multirow[t]{5}{*}{1} & Fen:ütiban Teraklii & ShP & 17 & $15,7 \%$ \\
\hline & & shan & 38 & $3 ., 7, \mathrm{~h}$ \\
\hline & & 51 & .19 & $.11,5 \%$ \\
\hline & & s) & 19 & $7, \sqrt{i} \%$ \\
\hline & & vill & $2 \mathrm{ve}$ & $200 \%$ \\
\hline
\end{tabular}

Tabel 1 menunjukan bahwa pengguna e-commerce shopee sebesar 108 responden, didominasi oleh perempuan dengan frekuensi 55 orang sebesar (50,9\%). Berdasarkan usia berusia 23-28 tahun sebesar (33,3\%), berdasarkan pekerjaan responden berstatus karyawan swasta sebanyak 33 sebesar (30,6\%), berdasarkan pendidikan terakhir berstatus lulusan SMA sebanyak 38 sebesar $(35,2 \%)$.

Tabel 2. Uji Validitas

\begin{tabular}{|c|c|c|c|}
\hline Item & R-hltung & R-Tabel & $\begin{array}{c}\text { Keteran } \\
\text { gan }\end{array}$ \\
\hline \multicolumn{3}{|l|}{ Variabel Kemudatan } \\
\hline Item 1 & 0.858 & 0.189 & Valid \\
\hline Item ? & 0 ถ27 & 0189 & Valid \\
Itcm 3 & 0796 & 0189 & Valid \\
\hline Item 1 & 0.717 & 0.189 & Valid \\
\hline Ilem 5 & 0.761 & 0.189 & Vulid \\
\hline Ilem 6 & 0.817 & 0.189 & Valid \\
\hline Item 7 & 0.776 & 0.189 & Valid \\
\hline Item 8 & 0.190 & 0.189 & Valid \\
Item 9 & 0.857 & 0109 & Valid \\
Iten 10 & 0.817 & 0.189 & Valid \\
\hline
\end{tabular}

\begin{tabular}{|c|c|c|c|}
\multicolumn{4}{|l|}{ Variabel Manfaat } \\
\hline Item 1 & 0.864 & 0.189 & Valid \\
\hline Item 2 & 0.926 & 0.189 & Valid \\
\hline Item 3 & 0.911 & 0.189 & Valid \\
\hline Item 4 & 0.911 & 0.189 & Valid \\
\hline Item 5 & 0.871 & 0.189 & Valid \\
\hline Item 6 & 0.901 & 0.189 & Valid \\
\hline Item 7 & 0.872 & 0.189 & Valid \\
\hline Item 8 & 0.906 & 0.189 & Valid \\
\hline Item 9 & 0.897 & 0.189 & Valid \\
\hline Item 10 & 0.885 & 0.189 & Valid \\
\hline
\end{tabular}

\begin{tabular}{|l|l|l|l|}
\hline \multicolumn{3}{|l|}{ Variabel Persepsi Resiko } \\
\hline Item 1 & 0.856 & 0.189 & Valid \\
\hline Item 2 & 0.837 & 0.189 & Valid \\
\hline Item 3 & 0.644 & 0.189 & Valid \\
\hline Item 4 & 0.846 & 0.189 & Valid \\
\hline Item 5 & 0.799 & 0.189 & Valid \\
\hline Item 6 & 0.818 & 0.189 & Valid \\
\hline Item 7 & 0.821 & 0.189 & Valid \\
\hline Item 8 & 0.814 & 0.189 & Valid \\
\hline Item 9 & 0.647 & 0.189 & Valid \\
\hline Item 10 & 0.835 & 0.189 & Valid \\
\hline \hline
\end{tabular}

Variabel Kepuasan Belanja Online

\begin{tabular}{|c|c|c|c|}
\hline Item 1 & 0.865 & 0.189 & Valid \\
\hline Item 2 & 0.817 & 0.189 & Valid \\
\hline Item 3 & 0.855 & 0.189 & Valid \\
\hline Item 4 & 0.757 & 0.189 & Valid \\
\hline Item 5 & 0.751 & 0.189 & Valid \\
\hline Item 6 & 0.741 & 0.189 & Valid \\
\hline Item 7 & 0.84 & 0.189 & Valid \\
\hline Item 8 & 0.791 & 0.189 & Valid \\
\hline Item 9 & 0.817 & 0.189 & Valid \\
\hline Item 10 & 0.812 & 0.189 & Valid \\
\hline
\end{tabular}

Dari analisis uji validitas dalam tabel 2 diketahui nilai $r$ hitung pada masingmasing pernyataan lebih tinggi dari $\mathrm{R}$ tabel jadi dapat diartikan pernyataan pada 
observasi bersifat valid sehingga dapat

\begin{tabular}{llrl}
\hline & & \multicolumn{2}{c}{ Colinearity Statistics } \\
Model & & Iclerance & \multicolumn{1}{l}{ VIF } \\
\hline 1 & (Constant) & & \\
& Kemudahan & .989 & 1.011 \\
& Manfaa: & .975 & 1.025 \\
& Fersepsi Risik. & .985 & 1.015 \\
\hline
\end{tabular}

dipakai untuk alat ukur.

Tabel 3. Uji Reliabilitas

\begin{tabular}{|c|c|c|c|}
\hline Variabel & Hasil & $\begin{array}{l}\text { Nilai } \\
\text { krititis }\end{array}$ & $\begin{array}{c}\text { Keterang } \\
\text { an }\end{array}$ \\
\hline Konuda & 0,939 & 0,30 & reliakt \\
\hline Mar'iax & 0,972 & 0.30 & reliakel \\
\hline Persepsi Kesiko & 0,933 & 0,30 & reliabel \\
\hline Kepuasan belarja online & 0939 & 0,30 & rellabel \\
\hline
\end{tabular}

Dari hasil analisis dalam tabel 3 ditemukan perhitungan Alpha Conbrach terhadap beberapa variabel $>0,60$ maka dapat dikatakan pernyataan dalam analisis bersifat reliabel.

Table 4. Uji Normalitas

\begin{tabular}{|c|c|c|}
\hline & & $\begin{array}{c}\text { Unstandardized } \\
\text { Besidinal }\end{array}$ \\
\hline N & & 108 \\
\hline \multirow[t]{3}{*}{ Normad Paramzerseb } & Mean & .0000000 \\
\hline & Std. & 512002519 \\
\hline & Devistion & \\
\hline \multirow{3}{*}{ Ment Fixtnoma Daflerances } & Akselute & 076 \\
\hline & Posittre & .045 \\
\hline & Negative & -.076 \\
\hline lest Statistic & & $.0 \% 0$ \\
\hline Lavaip $S_{\text {g }}$ (2-tsiled) & & 199 \\
\hline
\end{tabular}

Dari uji coba normalitas dalam tabel 4 menunjukan perhitungan Asymp. Sig. (2tailed) senilai 0,130>0,05 dengan begitu data dalam penelitian ini bersifat berdistribusi Normal.
Tabel 5. Uji Multikolinearitas

Dari uji coba multikolinearitas terhadap tabel 4.11 menunjukan perolehan Tolerance pada setiap variabel $>0,10$ dan jumlah vif $<10$ jadi dapat disimpulkan tidak menimbulkan multikoliniearitas atau tidak ada kesamaan antar variabel bebas.

Gambar 2. Hasil Uji Heterokedastisitas

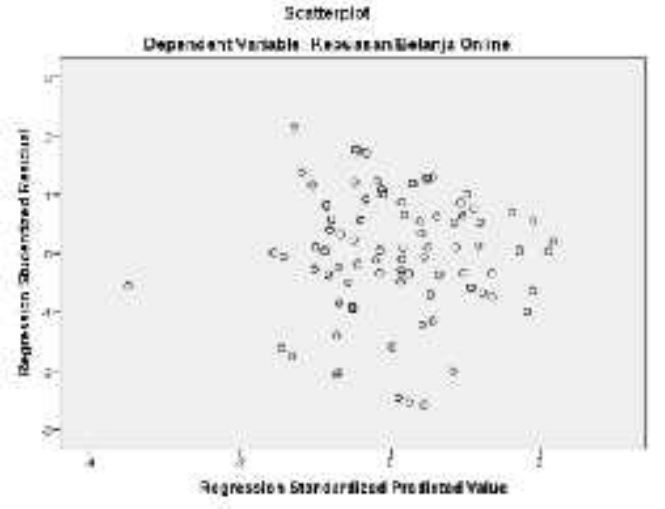

Dari kesimpulan analisis dalam gambar tidak ditemukan adanya pola yang teratur, serta bintik-bintik menebar di sekitar angka 0 terhadap sumbu sumbu $Y$, sehingga tidak menimbulkan heterokedastisitas.

Tabel 6. Regresi Linear Berganda

\begin{tabular}{|c|c|c|c|}
\hline \multirow[b]{2}{*}{ Model } & & \multicolumn{2}{|c|}{ Unstandardized Cxeffcients } \\
\hline & & $\mathrm{E}$ & Std. Exro? \\
\hline 1 & (Constant) & 15.763 & $5.190^{\circ}$ \\
\hline & Kemudahar. & 211 & .084 \\
\hline & Maniaa: & 249 & .069 \\
\hline & Fersepsi Risikc & .183 & .084 \\
\hline
\end{tabular}

Berdasarkan tabel 6 diperoleh hasil analisis dibawah ini : 
1. Konstanta sejumlah 15,763 menunjukan asalkan variabel dependen yaitu kemudahan, Manfaat, dan Persepsi Risiko dianggap konstan, maka Kepuasan Belanja mendapat penilaian sebesar 15,763.

2. Koefisien regresi (b1) sejumlah 0,211 menunjukkan jika Kemudahan (X1) ada peningkatan sebesar satu persen maka kepuasan belanja $(Y)$ dapat meningkat 0,211 dengan anggapan variabel Manfaat (X2) dan Persepsi Resiko (X3) bersifat konstan.

3. Koefisien regresi (b2) sebesar 0,249 memberikan arti bahwa Manfaat (X2) ada peningkatan sebesar satu persen maka Kepuasan Belanja ( $Y$ ) akan meningkat 0,249 apabila kemudahan (X1) dan persepsi resiko $(\mathrm{X} 3)$ bersifat konstan.

4. Koefisien regresi (b3) sebesar 0,188 memberikan arti bahwa persepsi Resiko (X3) ada peningkatan sebesar satu persen maka Kepuasan Belanja $(Y)$ meningkat 0,188 dengan anggpan variabel Kemudahan (X1) dan Manfaat (X2) dianggap konstan.

\section{Pengujian Hipotesis dan Pembahasan Hasil Penelitian}

Tabel 7. Hasil Uji t

\begin{tabular}{llll}
\hline & & & \\
Mordel & & + & 5ig. \\
\hline 1 & (Constant) & 3.054 & .003 \\
& Kemudahan & 2.530 & .013 \\
& Manfaat & 3.570 & .001 \\
& Fersepsi Risiko & 2.259 & .026 \\
\hline
\end{tabular}

Berdasarkan nilai t tabel dari jumlah responden 108 yaitu sebesar 1,982. Dari hasil output pada tabel 7 menunjukan jika:

Variabel Kemudahan berdampak secara pasti dan relevan kepada kepuasan belanja online dalam menggunakan e-commerce Shopee di Kelurahan Tanjungsari, Taman Sidoarjo, dengan ditunjukan dari besarnya hasil perolehan t hitung 2,530 >t tabel $=1,982$ dengan taraf sign $0,013<0,05$, agar diperoleh pernyataan seperti dibawah ini. $\mathrm{H} 1$ : Kemudahan berdampak secara pasti dan relevan kepada kepuasan belanja online dalam menggunakan e-commerce Shopee di Kelurahan Tanjungsari, Taman Sidoarjo.

Variabel Manfaat berdampak secara pasti dan relevan kepada kepuasan belanja online dalam menggunakan ecommerce Shopee di Kelurahan Tanjungsari, Taman Sidoarjo, dengan ditunjukan dari besarnya hasil perolehan $\mathrm{t}$ hitung 3,579 >t tabel=1,982 dengan taraf sign $0,001<0,05$. agar diperoleh pernyataan seperti dibawah ini.

H2: Manfaat berdampak secara pasti dan relevan kepada kepuasan belanja online dalam menggunakan e-commerce Shopee di Kelurahan Tanjungsari, Taman Sidoarjo.

Variabel Persepsi Risiko berdampak secara pasti dan relevan kepada kepuasan belanja online dalam menggunakan e-commerce Shopee di Kelurahan Tanjungsari, Taman Sidoarjo, dengan ditunjukan dari besarnya hasil perolehan t hitung 2,253 > t tabel $=1,982$ dan taraf sign 0,026 <0,05 agar diperoleh pernyataan seperti dibawah ini 
H3 : Risiko berdampak secara pasti dan relevan kepada kepuasan belanja online dalam menggunakan e-commerce Shopee di Kelurahan Tanjungsari, Taman Sidoarjo

Tabel 8. Hasil Uji $f$

\begin{tabular}{llll}
\hline Model & & F & Sig. \\
\hline 1 & Regression & 9.648 & $.000^{\mathrm{b}}$ \\
& Residual & & \\
& Total & & \\
\hline
\end{tabular}

Menurut tabel 8, Variabel Kemudahan, Manfaat, dan Persepsi Resiko secara keseluruhan mempunyai berdampak terhadap kepuasan belanja online dalam menggunakan e-commerce Shopee di Kelurahan Tanjungsari, Taman Sidoarjo, dengan ditunjukan dari besarnya perhitungan secara relevan $0,000<0,05$. Agar diperoleh pernyataan sebagai berikut.

H4 : Kemudahan, manfaat dan persepsi risiko berdampak secara pasti dan relevan kepuasan belanja online dalam menggunakan e-commerce Shopee di Kelurahan Tanjungsari, Taman Sidoarjo.

\section{SIMPULAN}

1. Variabel Kemudahan berdampak secara pasti dan relevan kepada kepuasan belanja online dalam menggunakan e-commerce Shopee di Kelurahan Tanjungsari, Taman Sidoarjo.

2. Variabel Manfaat mempunyai nilai pasti dan jelas dalam kepuasan Belanja online pada saat menggunakan e-commerce Shopee di Kelurahan Tanjungsari, Taman Sidoarjo.

3. Variabel Persepsi Resiko mempunyai nilai positif dan signifikan terhadap kepuasan belanja online dalam menggunakan e-commerce Shopee di Kelurahan Tanjungsari, Taman Sidoarjo.

4. Variabel Kemudahan, Manfaat, dan Persepsi Resiko secara serempak mempunyai nilai positif terhadap kepuasan belanja online dalam menggunakan e-commerce Shopee di Kelurahan Tanjungsari, Taman Sidoarjo.

\section{IMPLIKASI}

1. Masih minimnya pengetahuan seseorang tentang belanja online sehingga ada beberapa konsumen yang merasa kesulitan dan ribet ketika akan melakukan belanja online.

2. Adanya kesulitan untuk mendapakan promo gratis ongkir, sehingga konsumen merasa kurang puas pada saat melakukan belanja online di shopee.

3. Adanya risiko kerugian yang ditanggung konsumen, seperti performance barang tidak sesuai gambar, adanya tindak kejahat seperti penipuan setelah proses pembayaran produk tidak diterima dan produk cacat pada saat proses pengiriman.

4. Banyaknya toko offline yang tutup dan mengalami kerugian akibat masyarakat lebih memilih belanja online. 


\section{KETERBATASAN PENELITIAN}

1. Penelitian hanya dapat diuji cobakan terhadap masyarakat yang telah menggunakan aplikasi belanja online di shope dan tidak ditujukan pada aplikasi belanja online lainnya, sehingga kurang mencerminkan variabel kepuasan dalam belanja online.

2. Sampel hanya dapat diteliti pada satu kelurahan saja, jika boleh sampel diambil dari semua kelurahan yang terdapat di Kecamatan Taman, Sidoarjo, untuk mencakup lingkungan yang lebih luas.

3. Peneliti mengalami kesulitan untuk menghitung jumlah populasi dikarenakan tidak mengetahui secara pasti, sehingga populasi sulit dihitung dengan tepat.

4. Peneliti hanya meneliti 3 faktor yang mempengaruhi kepuasan transaksi online, seharusnya beberapa faktor lain juga dapat digunakan untuk mengukur kepuasan belanja online misalnya promo dan diskon.

\section{DAFTAR RUJUKAN}

Iwan Sidharta, Boy Suzanto, 2015, Pengaruh Kepuasan Transaksi Online Shopping Dan Kepercayaan Konsumen Terhadap Sikap Serta Perilaku Konsumen Pada ECommerce, Jurnal Computech_Bisnis, Vol.9, No.1, Juni 2015, 23-26 ISSN 2442-4943. (http://www.jurnal.stmikmi.ac.id), diakses tgl 10 november 2019).
Ilham, Saifulloh Akhmad, 2019, Pengaruh Persepsi Manfaat Dan Risiko Terhadap Keputusan Pembelian Menggunakan Flashsale Shopee di Kalangan Mahasiswa FEBI Universitas Islam Negeri Sunan Ampel Surabaya.

Awliya afwa dan Samsir dan Lilis Sulistyowati, 2014, Pengaruh Persepsi Teknologi, Persepsi Risiko Terhadap Kepercayaan dan Dampaknya Terhadap Kepuasan Belanja Online Mahasiswa di Pekanbaru, Jurnal Ekonomi, Vol. 22 Nomor 3 pp: $1-15$ https://je.ejournal.unri.ac.id, diakses tanggal 11 november 2019.

Moch Suhir, Imam Suyadi dan Riyadi, 2014, Pengaruh persepsi risiko, kemudahan dan manfaat terhadap keputusan pembelian secara online (Survei terhadap penguna situs website www.Kaskus.co.id), Jurnal Administrasi Bisnis (JAB) Vol. 8 No. 1 $\mathrm{pp}$ :

http://administrasibisnis.studentjourna l.ub.ac.id/ diakses tanggal 11 November 2019.

Zendy, AP, 2018, Analisis pengaruh fungsi aplikasi, kegunaan, dan manfaat yang dirasakan terhadap kepuasan pelanggan shopee belanja online di Yogyakarta, Jurnal Ekobis Dewantara Vol.2 No. 2 Thn 2019 Hal 1-17. http://jurnalfe.ustjogia.ac.id diakses tanggal 25 November 2019. 
